\title{
COMPARATIVE STUDY OF ROTAVIRUS DETECTION
}

\author{
Ibrahim B. Salwa ${ }^{1}$,El-Bialy A. A. , Mervat S. Mohamed ${ }^{1}$, Azza O. El-Sheikh ${ }^{1}$ and Elhewala $A^{2}$ \\ 1. Medical Microbiology \& Immunology Department, Faculty of Medicine, Zagazig University. \\ 2. Pediatric Department, Faculty of Medicine, Zagazig University.
}

\begin{abstract}
Background \& objectives: Rotavirus is the major cause of acute gastroenteritis (AGE) in infant and young children all over the world. The objective of the study was to compare different methods for rotavirus detection

Methods: This study included 65 children with AGE and 35 healthy control. Stool samples were obtained and assayed for rotavirus by immunochromatography test (ICT), enzyme linked immunosorbent assay (ELISA) and quantitative real time RT-PCR (qr RT-PCR).

Results: 50(76.9\%) out of the 65 patients were positive by qrRT-PCR followed by $45(69.2 \%$ ) by ICT and $44(67.7 \%)$ by ELISA. In addition there was statistically significant association between the severity of the disease as determined by the Vesikari score and rotavirus infection.

Conclusion and recommendation: This study highlights the substantial health burden of rotavirus AGE among children less than 5 years of age. These data should help pediatricians and policy makers assess the potential benefits of introducing a rotavirus vaccine.
\end{abstract}

Key words: Rotavirus- Acute gastroenteritis (AGE)- Vesikari score- Quantitative real time RT-PCR (qr RT-PCR).

\section{INTRODUCTION}

D iarrheal disease is one of the most important worldwide causes of morbidity and mortality, accounting for an estimated 1.3 million deaths in children under 5 years of age (1).

Rotavirus is the major cause of acute gastroenteritis and severe dehydrating diarrhea in young children (2).

The majority of morbidity and mortality caused by rotavirus gastroenteritis is experienced by children under 5 years of age in developing countries. Rotavirus causes approximately 453,000 deaths annually in children, most of them occurring in developing countries in Africa and South Asia (3).

Moreover, approximately $40 \%$ of hospitalizations for diarrheal illness that occur among children under 5 years of age in developing countries are due to rotavirus (4 and 5).

Clinically, rotavirus gastroenteritis is characterized by profuse diarrhea, mild fever and vomiting, leading to mild to severe dehydration. However, the clinical manifestations of rotavirus diarrhea alone are not sufficiently distinctive to permit diagnosis (6) and laboratory testing is the only way to confirm the diagnosis (7).

Most intractable diarrheas are treated with antibiotics, irrespective of the causative agent. If infection due to rotavirus can be diagnosed early, the misuse of antibiotics can be avoided (8).

Etiological diagnosis may not be essential in the treatment of individual patients but the knowledge of relative importance and seasonal prevalence of different pathogens in different regions is essential for proper management of outbreaks and the planning and implementation of control measures (8).
Several techniques have been developed to detect rotavirus in stool, including electron microscopy, polyacrylamide gel electrophoresis of viral nucleic acid, various immuno assays, and PCRbased molecular methods (9).

Several rapid methods as immunochromatographic test and latex Agglutination have been evaluated and compared to other methods as ELISA and quantitative real time RT- PCR (qr RT-PCR) and showed a wide range of sensitivity and specificity (10). The performance of those rapid tests indicated that the tests could only be used for screening but not for confirmation tests. Therefore, a high specific and sensitive test is mostly needed for confirmation of rotavirus infection (11).

\section{AIM OF THE WORK}

This study aims to compare between different methods for Rotavirus detection and correlation of Vesikari clinical severity scoring system with viral load.

\section{SUBJECTS, MATERIAL \& METHODS}

This work was carried out in the Microbiology \& Immunology Department and Pediatric department, Faculty of Medicine, Zagazig University \& hospitals and research laboratory Colors for Research, Maadi, Cairo during the period from October, 2013 to Mars, 2014.

\section{A-Subjects:}

\section{- $\quad$ Patient group:}

A total of 65 children aged less than 5 years $(2.3 \pm 0.9)$ suffering from AGE [AGE was defined by WHO as diarrhea $\geq 3$ watery or loose stools within 24 hours for $<14$ days at enrollment], admitted in pediatric hospital or visiting emergency department were included in the study. Institutional review board approval for the study 
was obtained before initiation of the study. It included 37 males and 28 females.

Exclusion criteria were as follows: chronic diarrhea which was defined as diarrhea that lasted for more than two weeks.

Written informed consent was obtained from parents/guardians before enrolment.

\section{- Control group:}

Consisted of 35 healthy children free from diarrhea, vomiting and fever. It included 21 males and 14 females aged less than 5 years $(2.6 \pm 0.8)$. The patient and the control groups were almost matched in age and sex.

\section{B-Material and methods:}

(I) Sample collection:

Fresh stool samples were obtained within 24 to $48 \mathrm{~h}$ of admission. Sterile wide necked plastic containers were used to collect and transport the samples.
(II) Processing of the sample:

A) A macroscopic examination of the received samples was conducted as follows:

- Colour, consistency (formed / semiformed/ liquid), presence of blood, presence of mucus, presence of segments and / or worms.

B) Labeled stool samples were divided into aliquots and stored at $-20^{\circ} \mathrm{C}$ and $-80^{\circ} \mathrm{C}$ until assayed for detection of rotavirus antigen and nucleic acid respectively.

(III) Assessment of Severity:

Clinical severity of disease was assessed by examination of the child and interview of the parents/guardians by the study paediatrician using the 20 point scale of Vesikari (12) which is based on the frequency and severity of diarrhoea, episodes of vomiting, associated fever and dehydration. Vesikari score is illustrated in table (I) and (II).

Table I: Vesikari Clinical Severity Scoring System Parameters and Scores (12):

\begin{tabular}{|c|c|c|c|c|}
\hline \multirow[b]{2}{*}{ Parameters } & \multicolumn{4}{|c|}{ Score } \\
\hline & 0 & 1 & 2 & 3 \\
\hline Diarrhea duration (days). & 0 & $1-4$ & 5 & $\geq 6$ \\
\hline Maximal no. of diarrheal stools per $24-\mathrm{h}$ period & 0 & $1-3$ & $4-5$ & $\geq 6$ \\
\hline Vomiting duration (days). & 0 & 1 & 2 & $\geq 3$ \\
\hline Maximal no. of vomiting episodes per $24-\mathrm{h}$ period & 0 & 1 & $2-4$ & $\geq 5$ \\
\hline Maximal recorded fever, rectal, ${ }^{\circ} \mathrm{C}$ & $<37.0$ & $37.1-38.4$ & $38.5-38.9$ & $\geq 39.0$ \\
\hline Dehydration & None & $\mathrm{N} / \mathrm{A}$ & $1-5 \%$ & $\geq 6 \%$ \\
\hline Treatment & None & Rehydration & Hospitalization & \\
\hline
\end{tabular}

Table II: Vesikari Clinical Severity Scoring System Severity Rating Scale (12):

$$
\text { Severity Category }
$$

\begin{tabular}{cccc}
\hline Mild & Moderate & Severe & Maximum Score \\
\hline$<7$ & $7-10$ & $\geq 11$ & 20 \\
\hline
\end{tabular}


(IV) Detection of rotavirus by ICT:

RIDA® Quick Rotavirus kit (R- Biopharm, Germany) was used to detect rotavirus antigen in stool samples. It is a single-step, immunochromatographic lateral-flow test and it was carried out according to the manufacturer's instructions (13).

\section{(V) Detection of rotavirus by ELISA:}

RIDASCREEN® kit (R- Biopharm, Germany) was used to detect rotavirus antigen in stool samples. In this test, monoclonal antibodies against the product of the sixth viral gene (VP6) are used in a sandwich-type method. The assay was carried out according to the manufacturer's instructions (14).

(VI) Detection of rotavirus by qr RT-PCR (11): a. RNA extraction (11):

Preparation of the sample: $0.5-1.0 \mathrm{ml}$ of each stool sample was suspended in up to $5 \mathrm{ml}$ saline (i.e., up to $1: 10$ dilution) and mixed by brief vortexing.

The solution was clarified by centrifugation for 20 $\min$ at $5000 \mathrm{xg}$. Then $140 \mu \mathrm{l}$ of the supernatant was used as the starting material for RNA following the Viral RNA Mini Spin Protocol (Quiagen, USA).

RNA was extracted by QIAamp ${ }^{\circledR}$ Viral RNA Mini Kit, commercially available kit. Extraction was done automatically using the QIAcube instrument according to the manufacturer's instructions.

To determine the efficiency of the extraction protocol in removing the high levels of PCR inhibitors present in stool samples, Internal extraction control was introduced to samples following stool clarification and carried through the specimen preparation, amplification, and detection protocols.

\section{b. Real time RT-PCR (11):}

In this study one step qr RT-PCR approach was used which combines the reverse transcription and real-time PCR reaction in a single closed tube. PrimerDesign $^{\mathrm{TM}}$ genesig Kit for Rotavirus A (PrimerDesign Ltd, UK) was used for quantification of Rotavirus A genome using specific primer and probe mix for Rotavirus A which was detected through the FAM channel.

For copy number determination and as a positive control for the PCR set up, a positive control template was used to generate a standard curve of Rotavirus A copy number / cycle threshold value (Ct value). The $\mathrm{Ct}$ value is inversely proportionate to the viral load; the high $\mathrm{Ct}$ value the low viral load and vice versa.

To confirm the absence of contamination, a negative control reaction was included every time the kit was used. For this reaction, the RNAse/DNAse free water was used instead of template.

A separate real-time PCR primer/probe mix was used to detect the internal RNA extraction control. The Internal control was detected through the VIC channel.

To confirm extraction of a valid biological template, a primer and probe mix was used to detect the Actin Beta (ACTB) gene for selected sample. Detection of ACTB is through the FAM channel and it was not therefore possible to perform a multiplex for ACTB and the pathogen primers and so it was performed in a separate tube.

\section{Statistical analysis}

The statistical analysis was performed using SPSS 10 software.

\section{RESULTS}

This study was conducted on two groups, the patient group which included 65 patients with AGE and the control group which included 35 healthy children.

Table (1): Results of ICT, ELISA and qrRT-PCR among the studied groups.

\begin{tabular}{cccc}
\hline Total number of & \multicolumn{3}{c}{ No(\%) of samples positive by } \\
\cline { 2 - 4 } samples & ICT & ELISA & qrRT-PCR \\
\hline Cases & $45(69.2)$ & $44(67.7)$ & $50(76.9)$ \\
No=65 & & & \\
\hline
\end{tabular}

*The control group was negative by the three tests. Rotavirus was detected in 50(76.9\%) out of the 65 patients by qrRT-PCR followed by $45(69.2 \%)$ by ICT and 44(67.7\%) by ELISA (Table 1 ).

6 months had the least with 2(4.0). However, as In this study children within the age group 6-12 months had the highest rate of rotavirus infection with 27(54.0), while those within the age group 0regard rotavirus negative patients, children within the age group 12-24 had the highest rate with $5(33.3 \%)$ and those within the age group $0-12$ months had the least with 3(20.0). The data from this table were statistically studied and revealed 
statistically significant association. However, as regard sex distribution, rotavirus positive rate was similar in males and females.

Table (2): Relation between rotavirus infection and Vesikari score.

\begin{tabular}{ccccc}
\hline $\begin{array}{c}\text { Severity (Vesikari } \\
\text { scale) }\end{array}$ & $\begin{array}{c}\text { Rotavirus negative } \\
\mathbf{N o = 1 5}\end{array}$ & $\begin{array}{c}\text { Rotavirus positive } \\
\text { No=50 }\end{array}$ & $\mathbf{X}^{\mathbf{2}}$ & $\mathbf{P}$ \\
\hline Mild & $6(40.0 \%)$ & $6(12.0 \%)$ & 0.04 & 0.02 \\
\hline Moderate & $6(40.0 \%)$ & $16(32.0 \%)$ & & \\
\hline Sever & $3(20.0 \%)$ & $28(56.0 \%)$ & & \\
\hline
\end{tabular}

In table (2) it was noted that 28(56.0\%) of rotavirus positive cases had sever score while $16(32.0 \%)$ had moderate score and $6(12.0 \%)$ had mild score. On the other hand, 6(40.0\%) of rotavirus negative cases had moderate score and another $6(40.0 \%)$ had mild score while only $3(20.0 \%)$ had sever score.
When this data were statistically studied it revealed statistically significant association between the severity of the illness and rotavirus infection. In other words, cases with rotavirus infection were suffering from more severe illness than rotavirus negative cases.

Ct value

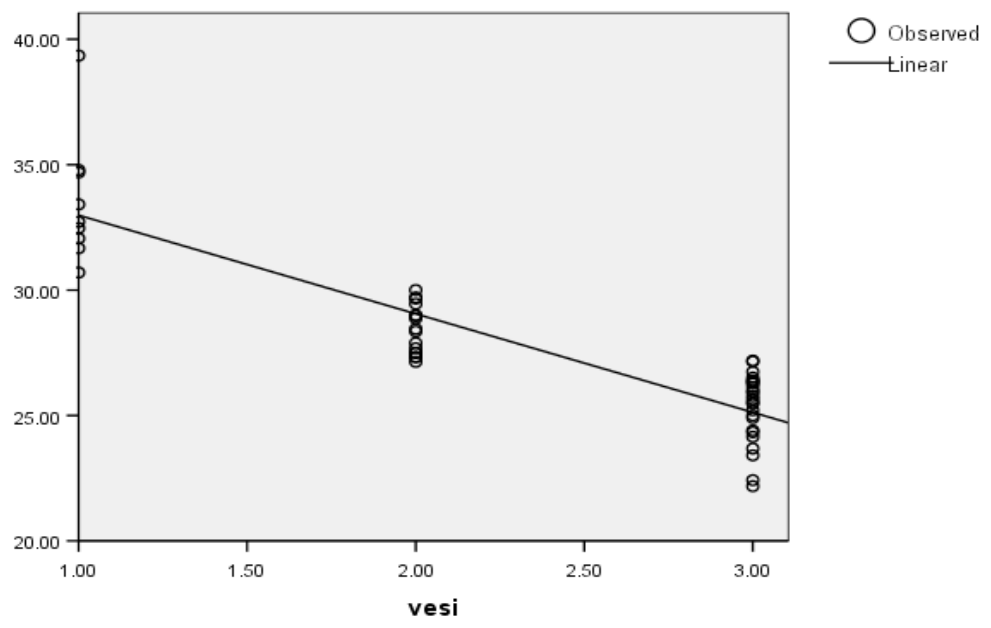

* $\mathbf{r}=0.89 \mathrm{P}<0.05$

Fig. (1): Plotting of the PCR Ct value versus Vesikari score and linear regression analysis.

Fig. (1) showed that the severity of diarrhea as determined by the Vesikari score is significantly and negatively associated with the PCR $\mathrm{Ct}$ value $(\mathrm{P}<0.05)$, indicating that children with severe diarrhea excrete more virus than children with less severe disease.

Table (3): Comparison of the results obtained by qrRT-PCR, ICT and ELISA.

\begin{tabular}{|c|c|c|c|c|}
\hline \multirow{2}{*}{\multicolumn{2}{|c|}{ Method }} & \multicolumn{2}{|c|}{ qrRT-PCR } & \multirow[t]{2}{*}{ Total } \\
\hline & & Positive & Negative & \\
\hline \multirow[t]{2}{*}{$\overline{I C T}$} & Positive & 45 & 0 & 45 \\
\hline & Negative & 5 & 15 & 20 \\
\hline \multirow[t]{2}{*}{ ELISA } & Positive & 44 & 0 & 44 \\
\hline & Negative & 6 & 15 & 21 \\
\hline \multicolumn{2}{|c|}{ Total } & 50 & 15 & 65 \\
\hline
\end{tabular}

According to the results in table 3 , the sensitivity, specificity, positive predictive value (PPV) and negative predictive value (NPV) were calculated using qr RT-PCR as a standard. As regard ICT these values were found to be $90.0 \%, 100.0 \%$, $100.0 \%$ and $75.0 \%$ respectively. On the other 
hand, for ELISA these values were $88.0 \%$, $100.0 \%, 100.0 \%$ and $71.0 \%$ respectively.
The results of ICT test are shown in fig. (2) and the results of the qrRT-PCR are shown in fig. (3), (4) and (5).

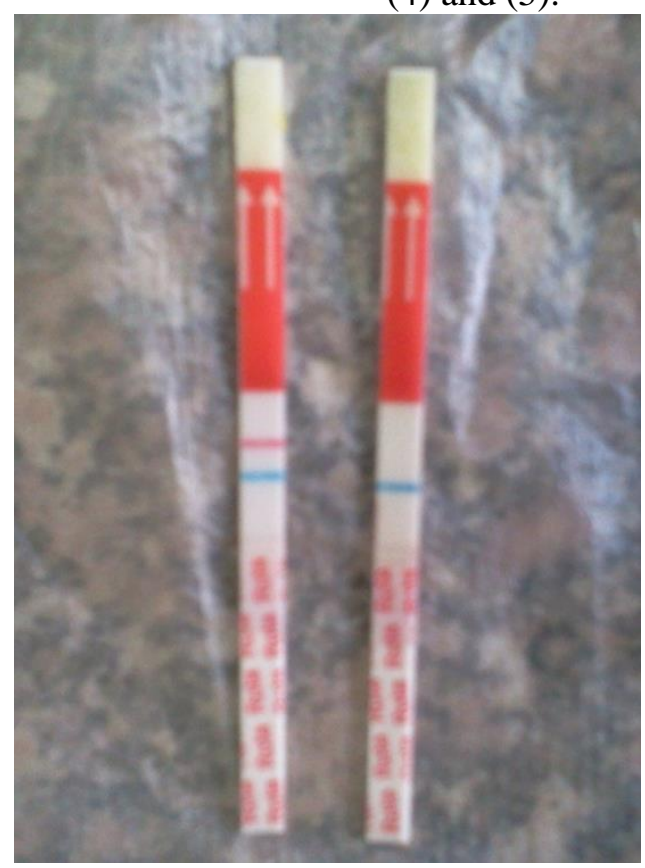

Fig.(2): ICT for rotavirus detection.

The strip to the left shows red and blue bands (rotavirus positive). The strip to the right shows only the blue band (rotavirus negative).



Fig. (3): Amplification Plot (Intensity of flourescence vs. Cycle) for rotavirus.

Intensity of flourescence is plotted against PCR cycle number where the intersection between an amplification curve and the threshold line is the $\mathrm{C}_{\mathrm{t}}$ (threshold cycle) a measure of the concentration of target rotavirus in the PCR reaction. Different colors represent different samples with different nucleic acid concentrations. 




Fig (4): Amplification Plot (Intensity of flourescence vs. Cycle) for the internal extraction control.

Intensity of flourescence is plotted against PCR cycle number where the intersection between an amplification curve and the threshold line is the $\mathrm{C}_{\mathrm{t}}$ (threshold cycle) a measure of the concentration of internal extraction control in the PCR reaction giving values ranging from 28 to 34 . The figure shows amplification of the internal extraction control so the results of the unknown samples are valid.

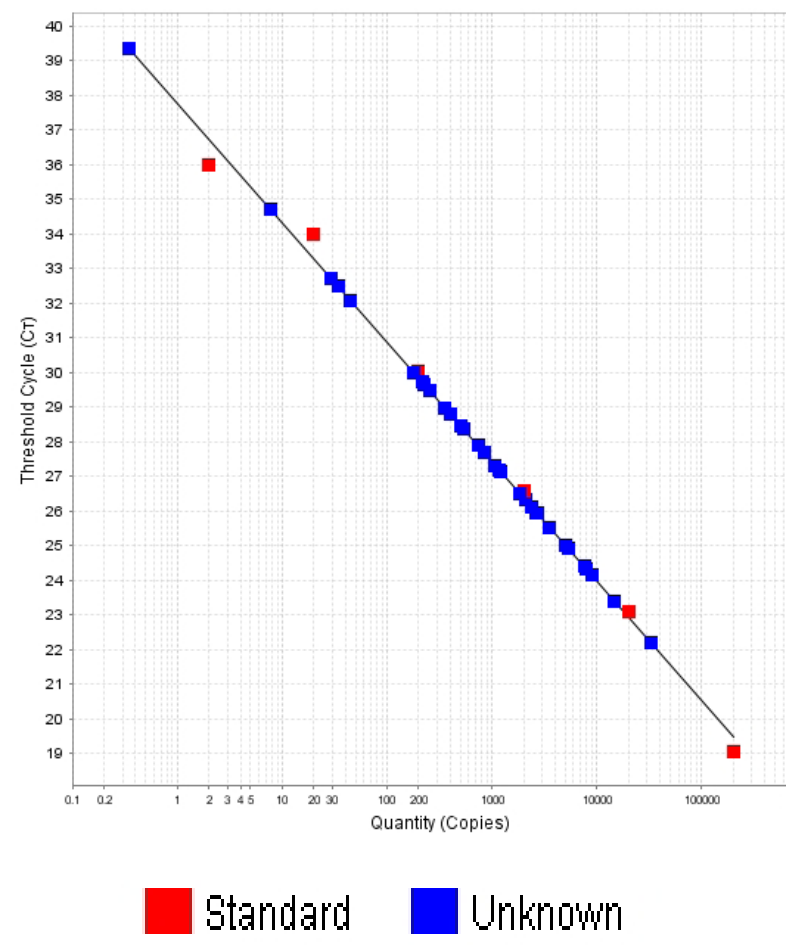

Fig. (5): Standard Curve of Rotavirus copy number / CT value.

The CT value is plotted against rotavirus copy number (quantity). Guided by the known copy number of the standards the copy number of rotavirus in the unknown samples can be determined. 


\section{DISCUSSION}

In the present study we compared between AGE patients and control groups as regard the detection of rotavirus by three different methods; ICT, ELISA and qrRT-PCR.

Fifty $(76.9 \%)$ cases had rotavirus in their stool by qrRT-PCR from a total of 65 cases. These results were in agreement with the results of Vainio et al. (15), who found that $72 \%$ of the children with diarrhea enrolled in their study from March 2006 to February 2008 had rotavirus in their stool by RT-PCR. Similarly, in the study conducted by Manjula (16) rotavirus accounts for $64 \%$ of hospitalization in children with acute diarrheal illness.

On the other hand lower figures were obtained by Ahmed et al. (17) who found that $40 \%$ of the cohort included in the study in Abu Homos, Beheira Governorate, Egypt, suffered at least one rotavirus diarrhea episode during the study period which extends from January 2004 through April 2007. However they reported higher frequencies $(65 \%)$ in children < 1 year when compared to older children.

Furthermore, in the later study rotavirusassociated diarrhea peaked in late summer (September) to late fall (November) similar to the trend reported in a population-based cohort study conducted by Naficy et al. (18) in Abu Homos, Egypt, during 1995-1998, where 90\% of rotavirus diarrheal episodes occurred between July and November. However in a much earlier study conduct in Bab El-Sha'reya University Hospital, Cairo, Egypt by El-Mougi et al. (19), rotavirus infection peaked from September to Mars. Ahmed et al. (17) explained this change in seasonality by subtle changes in various factors such as economic conditions, urbanization and population growth.

The high frequency reported in the present study may be explained by the fact that our study was conducted from September 2013 to Mars 2014 and these months fall in the period of high prevalence of rotavirus. However, in a systematic review of studies conducted by Malek et al. (20) concerning the epidemiology of rotavirus diarrhea in countries in the eastern Mediterranean region, the studies demonstrated circulation of rotavirus year-round and that seasonal fluctuation was less marked in some countries like Egypt and Iran. This difference in seasonality was explained by Mwenda et al. (21) by difference in the climatic conditions.

On the other hand no positive cases were detected among the control group by any of the tested methods. However, the detection of rotavirus in the control group varies widely between studies (22, 23 \& 24).

Nevertheless, because the above studies are from industrialized countries in which rotavirus vaccination is routine and vaccine virus was detected in percentage of the healthy controls, these findings might not apply to developing countries where the severity of infection, rates of asymptomatic viral shedding, and performance of the EIA may differ (24).

A Ct cut-off value of 24 was proposed by Phillips et al. (25) by comparing real-time PCR results to ELISA results in cases and asymptomatic controls for interpretation of real-time PCR results and relation to clinical symptoms.

Relating the Ct-value, as a quantification of viral load, to the severity of clinical symptoms to set up useful cut-off values seems an adequate approach to improve the interpretation of real-time PCR results. This method should solve an emerging clinical problem in the era of increased use of molecular diagnostic tools. However, the cut-off values mentioned above are not directly applicable to local real-time PCR results, because every PCR assay has different performance, and a local distribution and quantification of viruses can alter cut-off values (26).

In this study, children within the age group 6-12 months had the highest rate of rotavirus infection. Similar results were reported by EnweronuLaryea et al. (27) and Manjula (16).

On the other hand, in this study children within the age group 0-6 months had the least rate of rotavirus infection. This was in agreement with the results of Junaid et al. (28). This low incidence can be attributed to passive immunity acquired by the infants from their mothers which wades off after 6 months, and also possible, is the higher rate of breast feeding in this age group which also protects the infants via passing of $\operatorname{IgA}$ anti-rotavirus antibodies to the infants.

In this study there was no statistically significant association between sex and occurance of rotavirus infection. These results conformed to the results of Manjula (16). However, this is in contrast to the results of Nguyen et al. (29) where male predominance was noted and Junaid et al. (28), where boys have been found to be twice susceptible.

In the current study cases with rotavirus infection were suffering from more severe infection than rotavirus negative cases. These results were comparable to the results of Forster et al. (30) who found that AGE was more severe in rotavirus-positive subjects. 
In this study, there was a statistically significant negative association between the Vesikari score and PCR Ct value $(P<0.05)$ similar to what has been reported in other studies (31 and 32) indicating that children with severe disease excrete more virus than children with less severe disease.

Regarding the comparison between results obtained by qrRT-PCR, ICT and ELISA. The results of the current study agree with Wilhelmi $e t$ al. (33) and Khamrin et al. (34). And the authors concluded that ICT kits could be used as an alternative method for the rapid screening of group A rotavirus in fecal specimens especially during acute gastroenteritis outbreak season being rapid, inexpensive, easy to perform and required least amount of equipment.

\section{CONCLUSION}

This study highlights the substantial health burden of rotavirus AGE among children less than 5 years of age. In addition this study demonstrated that ICT is a useful method for the rapid screening of group A rotavirus in fecal specimens being rapid, inexpensive, easy to perform and required least amount of equipment.

\section{RECOMMENDATIONS}

This study provides data for assessing the potential benefits of introducing a rotavirus vaccine.

\section{REFERENCES}

1. Black RE, Cousens S, Johnson HL, Lawn JE, Rudan I, Bassani DG, Jha P, Campbell H, Walker CF, Cibulskis R, Eisele T and Liu L (2010): Global, regional, and national causes of child mortality in 2008: a systematic analysis. Lancet; 375:19691987.

2. Zuccotti G, Meneghin F, Dilillo D, Romanò L, Bottone R, Mantegazza C, Giacchino R, Besana R, Ricciardi G, Sterpa A, Altamura N, Andreotti M, Montrasio G, Macchi L, Pavan A, Paladini S, Zanetti A and Radaelli G (2010): Epidemiological and clinical features of rotavirus among children younger than 5 years of age hospitalized with acute gastroenteritis in Northern Italy. BMC Infect. Dis.;10:218-226.

3. Tate JE, Burton AH, BoschiPinto C, Steele D, Duque J and Parashar UD (2012): 2008 estimate of worldwide rotavirusassociated mortality in children younger than 5 years before the introduction of universal rotavirus vaccination programmes: a systematic review and meta-analysis. The Lancet Infectious Diseases; 12(2): $136-141$.

4. Parashar UD, Alexander JP and Glass RI (2006): Prevention of rotavirus gastroenteritis among infants and children. Recommendations of the Advisory Committee on Immunization Practices (ACIP). MMWR Recomm. Rep.; 55(12): 1-13.
5. World Health Organization (2008): Generic protocol for monitoring impact of rotavirus vaccination on gastroenteritis disease burden and viral strains. Geneva, Switzerland. Retrieved from: www.who.int/vaccines-documents/

6. Bass ES, Pappano DA and Humiston SG (2007): Rotavirus. Pediatr Rev.; 28: 183-191.

7. Bernstein DI, Ward RL (2004): Rotaviruses. In: Feigin RD, Cherry JD, eds. Textbook of Pediatric Infectious Diseases. 5th ed. Vol 2. Philadelphia, PA: Saunders; 2110-2133.

8. Chavan SC, Agarkhedkar S, Chavan DS, Nagdawane RP and Singhania S (2013): Prevalence of rotavirus diarrhoea among children hospitalized in a tertiary care hospital in Western India. Int $\mathbf{J}$ Pharm Biomed Sci.; 2013, 4(1): 4-7.

9. Logan C, O'Leary JJ and O'Sullivan N (2006): Realtime reverse transcription-PCR for detection of rotavirus and adenovirus as causative agents of acute viral gastroenteritis in children. J. Clin. Microbiol.;44:3189-3195.

10. Ferreira T, Becho MC, Bernardo AR, Chaves TCB, Ribeiro RS and de Lima JS (2006): Performance of A Latex Agglutination Test in The Diagnosis of Acute Gastroenteritis by Rotavirus. Brazilian J. Microbiol.; 37:587-589.

11. Yasmon A, Harahap ED, Dwipoerwantoro PG and Dewi BE (2010): Detection of human group A and $\mathrm{C}$ Rotaviruses in pediatric patients with acute gastroenteritis by real time RT-PCR assay: A preliminary study. Makara Kesehatan;14(2): 65-69.

12. Clark HF, Bernstein DI, Dennehy PH, Offit P, Pichichero M, reanor J and Heaton P (2004): Safety, efficacy, and immunogenicity of a live, quadrivalent human-bovine reassortant rotavirus vaccine in healthy infants. J. Pediatr.; 144(2): 184190.

13. Weitzel T, Reither K, Mockenhaupt FP, Stark K, Ignatius R, Saad E, Seidu-Korkor A, Bienzle U and Schreier E (2007): Field Evaluation of a Rotaand Adenovirus Immunochromatographic Assay Using Stool Samples from Children with Acute Diarrhea in Ghana. J Clin Microbiol.; 45(8): 26952697.

14. Eing BR, May G, Baumeister HG and Kühn JE (2001): Evaluation of Two Enzyme Immunoassays for Detection of Human Rotaviruses in Fecal Specimens. J Clin Microbiol.; 39 (12): 4532-4534.

15. Vainio K, Nordbø SA, Njølstad G, Størvold G, Døllner H, Midgaard C, Bosse FJ, Rognlien AG, Rojahn A, Wathne KO and Flem E (2009): Detection and characterization of group A rotaviruses in children hospitalized with acute gastroenteritis in Norway, 2006-2008. Journal of Medical Virology; 81(10): 1839-1844.

16. Manjula G (2013): Comparison of Immunochromatography with RT-PCR for Detection of Rotavirus in Fecal Samples. International Journal Of Scientific Research; 2:479481.

17. Ahmed SF, Mansour AM, Klena JD, Husain TS, Hassan KA, Mohamed F and Steele D 
(2014): Rotavirus Genotypes Associated with Acute Diarrhea in Egyptian Infants. Pediatric Infectious Disease Journal; 33:62-68.

18. Naficy AB, Abu-Elyazeed R, Holmes JL, Rao MR, Savarino SJ, Kim Y, Wierzba TF, Peruski L, Lee YJ, Gentsch JR, Glass RI and Clemens JD (1999): Epidemiology of rotavirus diarrhea in Egyptian children and implications for disease control. Am J Epidemiol.; 150:770-777.

19. El-Mougi M, Amer A, El-Abhar A, Hughes J and El-Shafie A (1989): .Epidemiological and clinical features of rotavirus associated acute infantile diarrhoea in Cairo, Egypt. J Trop Pediatr.; 35:230233.

20. Malek MA,Teleb N, Abu-Elyazeed R,Riddle MS,El Sherif1 M, Steele AD, Glass RI and Bresee JS (2010): The Epidemiology of Rotavirus Diarrhea in Countries in the Eastern Mediterranean Region. J Infect Dis.; 202(1): S12-S22.

21. Mwenda JM, Ntoto KM, Abebe A,EnweronuLaryea C, Amina I, Mchomvu J, Kisakye A, Mpabalwani EM, Pazvakavambwa I, Armah GE , Seheri LM, Kiulia NM, Page N, Widdowson MA and Steele AD (2010): Burden and Epidemiology of Rotavirus Diarrhea in Selected African Countries: Preliminary Results from the African Rotavirus Surveillance Network. J Infect Dis.; 202(1): 5-11.

22. Amar CFL, East CL, Gray J, Iturriza-Gomara M, Maclure EA, McLauchlin J (2007): Detection by PCR of eight groups of enteric pathogens in 4,627 faecal samples: re-examination of the English casecontrol infectious intestinal disease study (19931996). Eur J Clin Microbiol Infect Dis.; 26:311323.

23. Payne DC, Staat MA, Edwards KM, Szilagyi PG, Gentsch JR, Stockman LJ, Curns AT, Griffin M, Weinberg GA, Hall CB, Fairbrother G, Alexander J and Parashar UD (2008a): Active, population-based surveillance for severe rotavirus gastroenteritis in children in the United States. Pediatrics; 122(6):1235-1243.

24. Tate JE, Rustempasic SM, Tam KI, Lyde FC, Payne DC, Szilagyi P,Edwards K, Staat MA, Weinberg GA, Hall CB, Chappell J, McNeal M, Gentsch JR, Bowen MD and Parashar UD (2013): Comparison of 2 Assays for Diagnosing Rotavirus and Evaluating Vaccine Effectiveness in Children with Gastroenteritis. Emerg Infect Dis; 19(8): 1245-1252.

25. Phillips G, Lopman B, Tam CC, Iturriza-Gomara M, Brown D, Gray J (2009): Diagnosing rotavirus
A associated IID: Using ELISA to identify a cut-off for real time RT-PCR. J Clin Virol.; 44(3):242-245.

26. Corcoran MS, van Well GT and van Loo IH (2014): Diagnosis of viral gastroenteritis in children: interpretation of real-time PCR results and relation to clinical symptoms. Eur J Clin Microbiol Infect Dis; DOI 10.1007/s10096-014-2135-6.

27. Enweronu-Laryea CC, Sagoe KW, Addy HG, Asmah RH, Mingle JA and Armah GE (2012): Prevalence of severe acute rotavirus gastroenteritis and intussusceptions in Ghanaian children under 5 years of age. J Infect Dev Ctries.; 6(2):148-155.

28. Junaid SA, Umeh C, Olabode AO and Banda JM (2011): Incidence of rotavirus infection in children with gastroenteritis attending Jos university teaching hospital, Nigeria. Virology Journal; 8:233240.

29. Nguyen TV, Le Van P, Le Huy C and Weintraub A (2004): Diarrhea Caused by Rotavirus in Children Less than 5 Years of Age in Hanoi, Vietnam. J Clin Microbiol.; 42(12): 5745-5750.

30. Forster J, Guarino A, Parez N, Moraga F, Román E, Mory O, Tozzi A E., Aguileta A, Wahn U, Graham C, Berner R, Ninan T, Barberousse C, Meyer N and Gabarró MS (2009): Hospital-Based Surveillance to Estimate the Burden of Rotavirus Gastroenteritis among European children younger than 5 years of age. Pediatrics; 123(3): e393-e400.

31. Kang G, Iturriza-Gomara M, Wheeler JG, Crystal P, Monica B, Ramani S, Primrose B, Moses PD, Gallimore CI, Brown DW and Gray J (2004): Quantitation of Group A Rotavirus by Real-Time Reverse-Transcription-Polymerase Chain Reaction Correlation With Clinical Severity in Children in South India. J Med Virol.; 73(1): 118-122.

32. Wolffs PF, Bruggeman CA, van Well GT and van Loo IH (2011): Replacing Traditional Diagnostics of Fecal Viral Pathogens by a Comprehensive Panel of Real-Time PCRs. J. Clin. Microbiol.; 49 ( 5): 1926-1931.

33. Wilhelmi I, Colomina J, Martín-Rodrigo D, Roman E, Sánchez-Fauquier A (2001): New immunochromatographic method for rapid detection of rotaviruses in stool samples compared with standard enzyme immunoassay and latex agglutination techniques. Eur J Clin Microbiol Infect Dis.; 20(10):741-743.

34. Khamrin P, Tran DN, Chan-it W, Thongprachum A, Okitsu S, Maneekarn N and Ushijima H (2011): Comparison of the rapid methods for screening of group a rotavirus in stool samples. Journal of Tropical Pediatrics; 57(5):375-377. 